\title{
FIRE RESISTANCE OF A DAMAGED BUILDING EMPLOYING BUCKLING RESTRAINED BRACED SYSTEM
}

\author{
Elnaz Talebi ${ }^{1}$, Mahmood Md Tahir ${ }^{1, *}$, Farshad Zahmatkesh ${ }^{2}$, \\ Ahmad B.H. Kueh ${ }^{1}$ and Aly M. Said ${ }^{2}$ \\ ${ }^{1}$ UTM Construction Research Centre (UTM-CRC), Institute for \\ Smart Infrastructure and Innovative Construction (ISIIC), Faculty of Civil Engineering, \\ Universiti Teknologi Malaysia, 81310 Johor Bahru, Malaysia \\ ${ }^{2}$ Department of Architectural Engineering, the Pennsylvania State University, \\ University Park, PA 16802, USA \\ *(Corresponding author: mahmoodtahir@utm.my)
}

Received: 29 July 2016; Revised: 28 November 2016; Accepted: 14 February 2017

\begin{abstract}
This study investigates the influence of buckling restrained brace systems (BRBs) on the overall structural stability against fire following a severe incident, which caused the failure of a column on the first storey of a steel building. A four-storey moment frame fitted with the inverted-V arrangement of braces is modelled, considering a multi-hazard approach. This technique concentrates on a structural plane frame that is designed to meet the progressive collapse criteria according to the U.S. Department of Defense guidelines and assumes that an extreme event damaged a first-storey centre column, before the exposure to an ensuing fire. The performance of BRBs in preventing the global collapse of the structure due to a post-event fire is compared with that of ordinary concentric brace systems (OCBs). The results indicate that BRBs offer a higher global collapse time to the building owing to the greater stiffness they provide to the structural frame. The fire resistance provided by BRBs is restricted to the participation of bracing elements and framing girders afterwards. In the case of OCBs, columns contribute to the structural resistance prior to the full capacity of braces used. To conclude, it is found that BRBs are more capable in maintaining the stability of a damaged building against fire resulting from an extreme event than OCBs.
\end{abstract}

Keywords: Buckling restrained brace (BRB); Ordinary concentric brace (OCB); Progressive collapse; Damaged building; Fire response.

DOI: $10.18057 /$ IJASC.2018.14.1.1

\section{INTRODUCTION}

Progressive collapse is a continuous event that initiates by the local damage of structural loadbearing members and results in the disastrous global breakdown of the entire building. There have been several instances of progressive collapse, such as that of the London Ronan Point residential tower block in 1968 and the Oklahoma Alfred P. Murrah Federal Building in 1995. Since the partial collapse of the Ronan Point building in 1968 [1], the structural engineering community has faced significant challenges to prevent such alarming incident. In response to these and similar incidents, structural standards and building codes now include design guidelines and resistance criteria [2-4]. Recently, extensive research has been dedicated to investigating the progressive collapse resistance of various types of structural frames. Many of these studies have shown that seismically designed structural frames are less susceptible to the progressive collapse under the abrupt loss of column caused by severe incidents [5-7]. Kim et al., [8] compared the progressive collapse resistance provided by various steel braced frame systems with that of moment resisting frame (MRF). They showed that appending the braced systems to the structural moment frames enhanced the resistance of a building against progressive collapse, while the bracing systems remained stable after the abrupt column loss. $\mathrm{Fu}$ [9] demonstrated that using braced resisting systems with cross arrangement could 
noticeably improve the progressive collapse resistance of a multi-storey structure. Mohamed [10] suggested that the large forces generated due to the sudden removal of the column could be efficiently moderated by appending bracing members to the structural frame. Khandelwal et al., [11] demonstrated that altering the type of braced resisting systems from concentric to eccentric could successfully enhance the progressive collapse resistance of the entire structure. Although several studies have discussed the progressive collapse mechanisms of buildings with conventional bracing systems, none has considered the effect of applying improved types of bracing systems such as buckling restrained braces (BRB) on preventing the progressive collapse of structural frames subjected to extreme events.

It is well known that the strength of ordinary concentric braces (OCB) drops rapidly due to early buckling of compressive bracing components, before braces exhaust their capacity. This shortcoming in the response of OCBs has led to the development of buckling restrained braces. The compressive bracing elements in BRBs exhibit superior performance due to their buckling resistant characteristic compared to OCBs [12]. The principal advantages of BRB systems are high energy dissipation ability, high ductility and almost symmetrical hysteretic responses in tension and compression [13]. In terms of constituent components, BRBs are composed of a yielding steel core encased in a concrete-filled steel hollow casing to prevent buckling (Figure 1(a)), non-yielding and buckling-restrained transition parts as well as nonyielding and unrestrained end regions (Figure 1(b)). About $60 \%$ to $70 \%$ of the entire length of the core is restrained by the casing. In these bracing systems, compression stresses are mainly sustained by the restrained portion of the core. Furthermore, the yield strength of the steel core is much lower than that of steel tube casing. This allows the core to yield in the same manner during tension and compression prior to the casing, thus considerably enhancing the energy dissipation abilities of BRBs in comparison with ordinary bracing systems.

Because of Poisson's ratio effect on the steel core, it expands when it is compressed. To prevent the axial stress transition from the core to the restrainer (concrete filled-in steel tube casing), a certain amount of clearance between the core and concrete is provided to avoid friction (Figure 1(c)). In addition to this gap, a debonding agent is also applied to the surface of the core to minimize the friction between the core and concrete, as shown in Figure 1(a).

Due to the aforementioned advantages of BRBs, the main aim of this study is to evaluate the effectiveness of this system in maintaining the stability of a building damaged by an extreme event and subjected to a resulting fire.

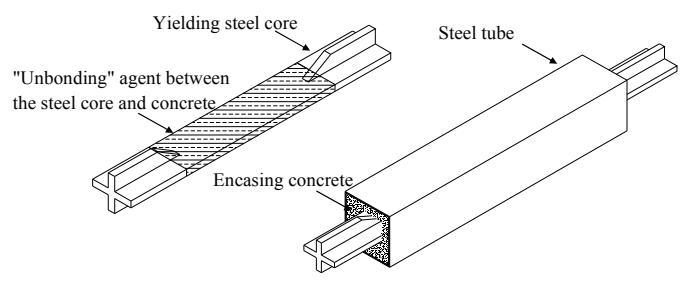

(a)

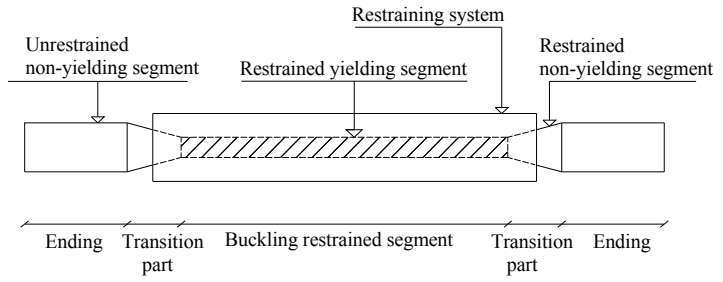

(b)

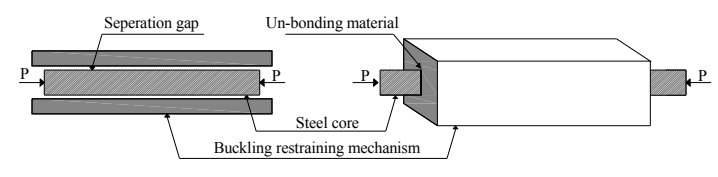

(c)

Figure 1. Detail of BRB: (a) General Structure, (b) Steel Core Constituent Segments and (c) Separation Gap at Steel Core-restrainer Interface [14] 
Although building guidelines [2-4] have improved the buildings' ability to withstand a collapse disproportionate to the damage suffered during a severe incident, current structural collapses have underlined the need to further improve the progressive collapse resistance of buildings damaged by a serious event then subjected to an ensuing fire. This situation is not clearly addressed in current progressive collapse design provisions. It can be however, crucial if a structure is to experience such incident. The majority of research on progressive collapse resistance of structures focuses on the events that put a building in danger of global collapse without considering a subsequent fire. This phenomenon has seldom been investigated. DellaCorte et al., [15] studied the response of a steel moment resisting frame under fire conditions after it had experienced permanent deformations caused by a seismic activity. Chen and Liew [16] estimated the resistance of columns under fire conditions in a steel building that had been damaged by a blast.

Owing to the limited literature on the aforementioned issue, this paper examines the response of a building damaged by a severe incident and subsequently subjected to an ensuing fire using a multi-hazard approach. For this purpose, a four-storey steel moment frame fitted with $\mathrm{BRB}$ elements and designed to resist progressive collapse in accordance with the guidelines given by the U.S. Department of Defense [3] is used as a prototype structure for study. The specified structural steel frame is assumed to be subjected to the sudden loss of the first-storey middle column due to a severe event and is subsequently exposed to a fire resulting from that event. The efficacy of BRBs in preventing the eventual structural collapse due to fire loading is compared with that of ordinary concentric brace systems (OCBs). To perform the analysis, a multi-hazard approach considering two main scenarios is utilized, namely the sudden loss of the first-storey middle column caused by an extreme event and the consequent fire. The detail of the modelling approach as well as the analysis sequence is described next.

\section{METHODOLOGY}

In order to assess the effect of bracing systems on maintaining the overall stability of a damaged steel building against fire, a multi-hazard approach is considered in this study. In this technique, first, the structure is subjected to a severe event (Stage 1 in Figure 2(a)). This is then followed by a sudden removal of the first-storey middle column, shown as Stage 2 in Figure 2 (b). After the column loss, the load previously carried by this column is redistributed to the adjacent members until the onset of stable plastic deformations as progressive collapse resistance takes place (Figure 2(b)). Finally, a severe fire in the vicinity of the removed column is developed as a result of the extreme event in stage 1 (Stage 3 in Figure 2(c)).

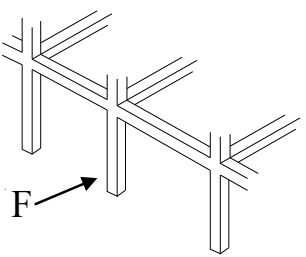

Stage 1 :

the structure is subjected to a severe event

(a)

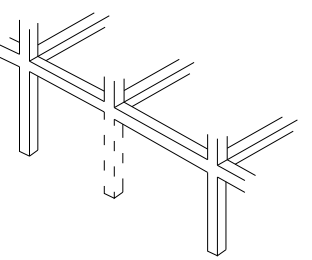

Stage 2 :

column loss, load redistribution and the formation of plastic deformations

(b)

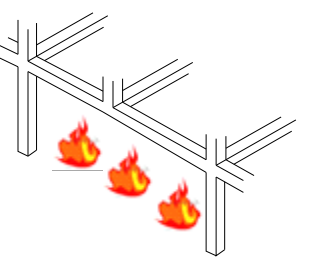

Stage 3:

post event fire

(c)

Figure 2. Stages considered in the Multi-hazard Approach as

(a) stage 1, (b) stage 2 and (c) stage 3 
Considering the sequential events illustrated in Figure 2, the analyses are performed according to the order described below. First, the progressive collapse analysis is performed through a sudden removal of the middle column to ensure that the building conforms to DoD guidelines [3]. In this stage, analysis is threat-independent and the reason for member failure is not taken into account. To simulate the progressive collapse phenomenon, the alternative path method is adopted. Two types of analysis are implemented, namely, the nonlinear static and the dynamic analyses, using the SAP2000 program version 14.0 Advanced [17]. Afterwards, the fire resistance of the damaged structure is evaluated. In this stage, it is presumed that the onset of fire is immediately after the structure reaches a stable permanent deformed shape caused by column loss. To perform the structural fire analysis, a two-dimensional nonlinear plane frame is modelled, using Vulcan program version 10.12.0 [18].

\subsection{Progressive Collapse Analysis}

The capacity of a structure to sustain gravity loads without collapse through redistributing the internal forces resulting from the abnormal loads defines its progressive collapse resistance. To perform an appropriate analysis for progressive collapse, it is essential to follow the sequence of failure occurrence within the structural elements. Accounting for the dynamic response when applying static analysis, both the GSA [2] and the DoD [3] proposed the application of twofold the load combination as a dynamic amplification factor (Figure 3).

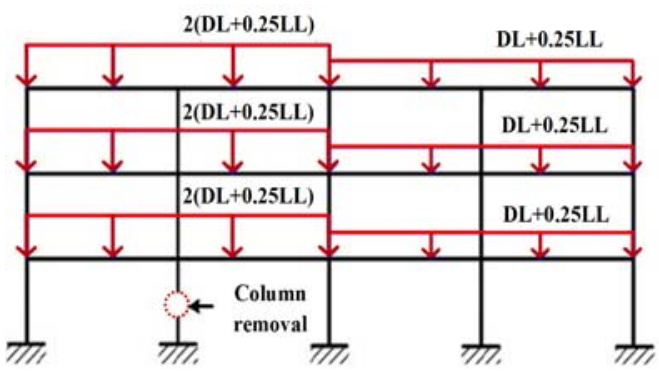

(a) Static method according to GSA, 2003

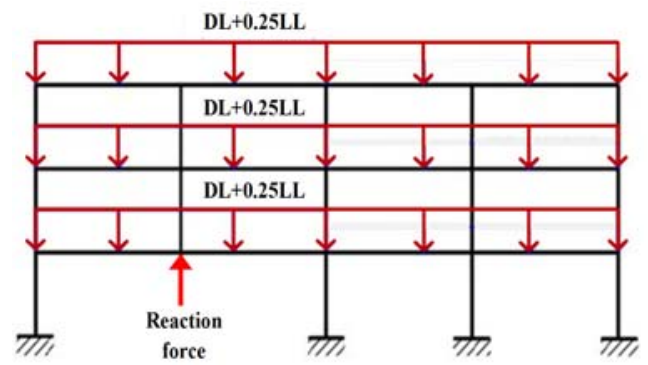

(c) Dynamic method according to GSA, 2003

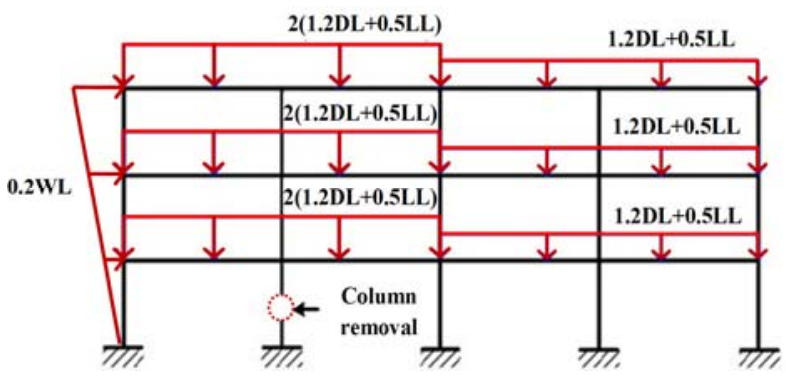

(b) Static method according to DoD, 2010

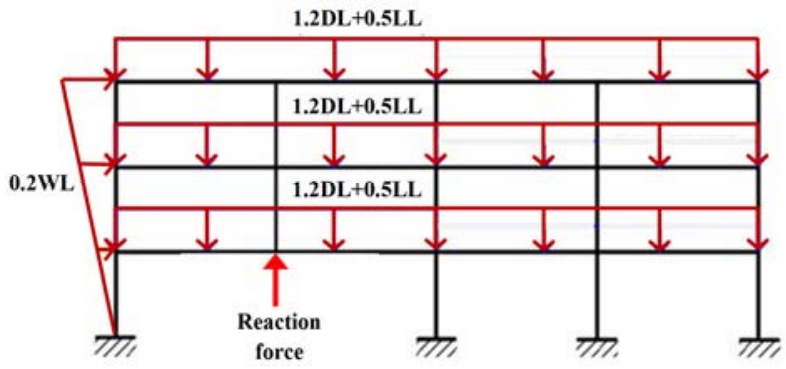

(d) Dynamic method according to DoD, 2010

Figure 3. Load Combinations used for the Progressive Collapse Analyses based on the GSA [2] and the DoD [3] guidelines

The nonlinear static pushdown (vertical pushover) analysis is implemented first, such that the response of the structural frame is verified by progressively enlarging the downward displacement in the top position of the lost column. The dynamic analysis is carried out afterwards, in which the column removal is simulated as follows. First, the reaction forces operating on a column specified for a remove scenario are calculated prior to its elimination. 
Next, the column is replaced by the computed forces on the node in the position of the corresponding column. Finally, these reaction forces are concurrently and suddenly brought to the zero value. Practically, this phenomenon can be simulated in the SAP2000 by imposing at the corresponding node an equal set of forces in the opposite direction, as shown in Figure 3.

In order to simulate the quick rate of column removal from an equilibrium condition, the reactions are eradicated after a certain time has elapsed (Figure 4). In the current study, the removal time is considered as $5 \mathrm{~ms}$, which connotes a quasi-instant elimination [20].

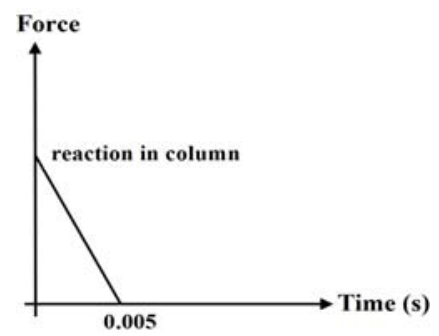

Figure 4. Time Histories of Applied Loads used for Simulation of Column Removal in Dynamic Analysis

\subsection{Structural Fire Analysis}

The fire resistance of a specified damaged structure is verified using the Vulcan program [18]. In Vulcan, beam-column structural members are modelled by three-noded line elements containing two Gaussian integration points along their length, and these elements are connected to each other at the nodal intersection points [19]. In this FE program, each line element can have different temperatures distributed across its cross-section, which leads to changes in the material properties and thermally induced strains at elevated temperatures. This is done by dividing each element into a matrix of segments. By means of this division, each part can have its own characteristics [19]. In this program, issues such as material thermal expansion and degradations in the stress-strain relationship are taken into account. Also, both material and geometric nonlinearities are considered in this FE program. With this information, Vulcan is adequate for the analysis of structural frames under fire conditions.

\section{NUMERICAL FE MODEL}

\subsection{Problem Description}

The effect of BRBs on maintaining the overall stability of structural frames is compared with that of an ordinary concentric braced system (OCBs). For this, a structural moment frame fitted with the inverted-V braces is modelled numerically. This type of bracing configuration has been established to offer an enhanced progressive collapse resistance due to a sudden column loss in comparisons to other bracing arrangements [8]. As shown in Figure 5, the specified structural plane frame has four storeys, each of which is $3.4 \mathrm{~m}$ high. There are four bays, each with a $6.0 \mathrm{~m}$ span, exposed to a sudden loss of the first-storey centre column (C3-1 in Figure 5), followed by the symmetrical deformation of the structural frame. In Figure 5, the sections are nominated such that each member's name comprises three main letters. The first letter corresponds to the element type, i.e., $\mathrm{C}$ for column and $\mathrm{Br}$ for braces. The second letter shows the element position while the third letter refers to a storey level, BrL-1 for instance denotes the left brace at the first storey. 


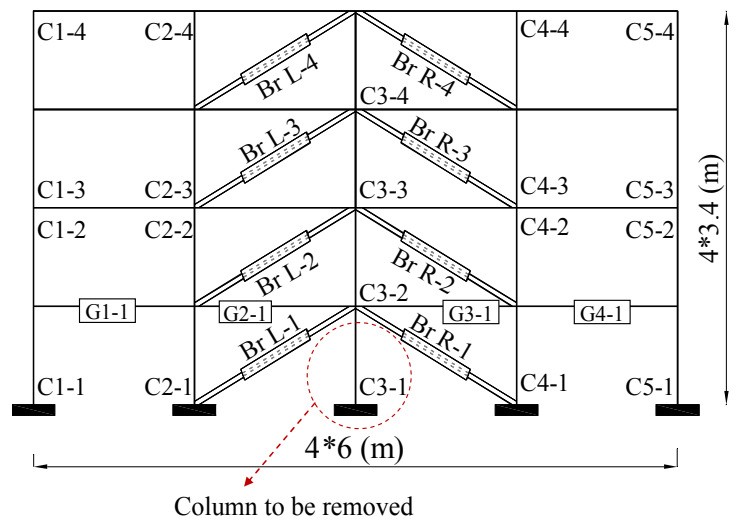

Figure 5. Structural Plane Frame with Inverted-V format of BRB Elements

The beams and columns are made of ASTM A992 steel and their section sizes are as listed in Table 1.

Table 1. Cross-sections of Beams and Columns

\begin{tabular}{lccc}
\hline Storey & \multicolumn{2}{c}{ Column section } & Beam section \\
& external & internal & \\
\hline Ground floor & W $5 \times 19$ & W $8 \times 40$ & W $21 \times 57$ \\
First floor & W5 $\times 19$ & W $8 \times 40$ & W $21 \times 57$ \\
Second floor & W $4 \times 13$ & W $5 \times 16$ & W $21 \times 57$ \\
Third floor & W4 $\times 13$ & W $5 \times 16$ & W $21 \times 57$ \\
\hline
\end{tabular}

The bracing elements for OCBs are rectangular hollow steel sections (HSS) (Figure 6(a)), made of ASTM A500-46 structural steel. Similarly, HSS are used as the steel tube casing in BRBs, while cores of rectangular sections with a nominal yield strength of $250 \mathrm{~N} / \mathrm{mm}^{2}$ (A36 steel) are inserted within the hollow sections (Figure 6(b)). Concrete used to fill the steel tube (restrainer) is of normal weight type with a density of $2400 \mathrm{~kg} / \mathrm{m}^{3}$. The compression strength and Poisson's ratio of concrete are $35 \mathrm{~N} / \mathrm{mm}^{2}$ and 0.2 , respectively. The section sizes used for the braces are as listed in Table 2.

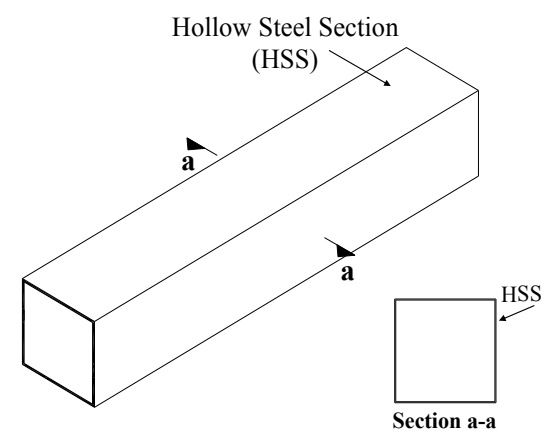

(a)

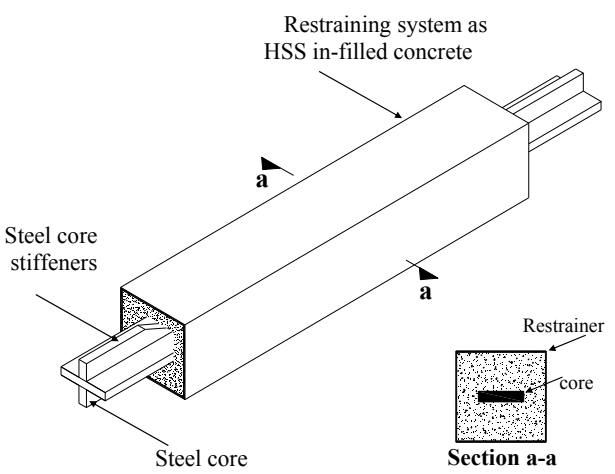

(b)

Figure 6. Overall Scheme and Cross-section of Braces for (a) OCB and (b) BRB Systems 
Table 2. Cross-sections of Bracing Elements used for Both Bracing Systems

\begin{tabular}{lccc}
\hline \multicolumn{1}{c}{ Storey } & \multicolumn{2}{c}{ BRB section } & OCB section \\
& Steel casing & Steel core $(\mathrm{mm})$ & \\
\hline Ground floor & HSS4- $1 / 2 \times 4-1 / 2 \times 0.3125$ & PL-70 $\times 16$ & HSS4-1/ $2 \times 4-1 / 2 \times 0.3125$ \\
First floor & HSS4- $1 / 2 \times 4-1 / 2 \times 0.3125$ & PL-70 $\times 16$ & HSS4- $1 / 2 \times 4-1 / 2 \times 0.3125$ \\
Second floor & HSS4- $1 / 2 \times 4-1 / 2 \times 0.3125$ & PL-70 $\times 16$ & HSS4- $1 / 2 \times 4-1 / 2 \times 0.3125$ \\
Third floor & HSS4- $1 / 2 \times 4-1 / 2 \times 0.3125$ & PL- $70 \times 16$ & HSS4- $1 / 2 \times 4-1 / 2 \times 0.3125$ \\
\hline
\end{tabular}

The specified structural plane frame is designed according to the AISC Load and Resistance Factor Design [21] and the Seismic Provisions for Structural Steel Buildings [22]. The design loads of $4.3 \mathrm{kN} / \mathrm{m}^{2}$ and $2.4 \mathrm{kN} / \mathrm{m}^{2}$ are assumed for dead and live loadings, respectively, and are uniformly distributed along the length of girders, accounting for the one-way behaviour of floor slabs. The building is designed seismically in accordance with the Minimum Design Loads for Buildings and Other Structures [4]. The parameters for design spectral acceleration, $S_{\mathrm{s}}$ and $S_{1}$, are derived as 1.5 and 0.6, respectively, considering the IBC-2006 format [23]. Correspondingly, the site coefficients of 1.0 and 1.5 are obtained for $F_{\mathrm{a}}$ and $F_{\mathrm{v}}$, respectively, using the response modification factors 6 and 7 for OCBs and BRBs, respectively. According to the AISC Seismic Provisions [22], the strength of bracing connections must be the smallest value of their nominal tensile strength and the maximum load they can sustain. Hence, in this study, the bracing connections are considered to remain elastic throughout the analysis and the plastic hinging is allowed only in braces.

\subsection{Modelling of Progressive Collapse Analysis}

Finite element (FE) analysis of the specified structural frame is conducted, using the SAP2000 Advanced [17]. Structural elements in the buildings are modelled as an assemblage of finite beam, column and braces. The buckling-restrained braces are modelled implicitly, considering a symmetrical response in tension and compression for defining the plastic hinges within the core elements. To simulate the restraining system in BRB elements, the in- and outof-plane rotations of the steel core are restrained. The numerical modelling leads to the formation of 228 nodes and 232 frame elements, as shown in Figure 7. For simplicity, the models are considered to be two-dimensional in this study, which may not benefit from the effect of out-of-plane structural elements and the floor systems. To provide the progressive collapse resistance of the structural frame, the beam-to-beam continuity is assumed to be preserved, once the column is removed.

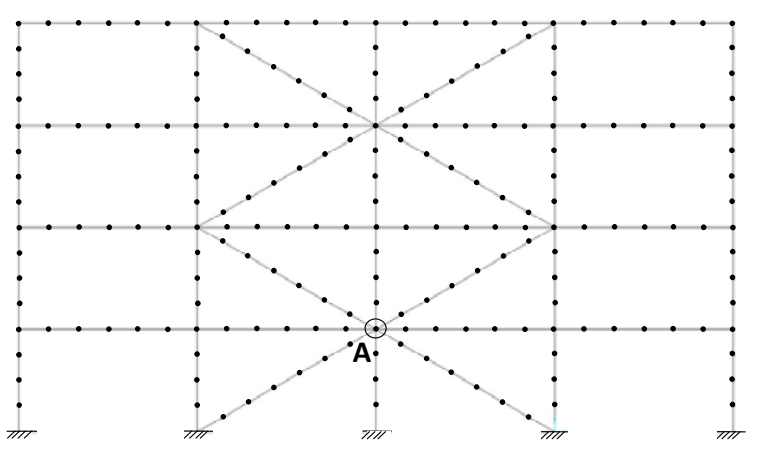

Figure 7. Finite Element Model of Structural Plane Frame in SAP2000 and its Associated Nodes and Elements 
In relation to the acceptance criteria for progressive collapse analysis, the GSA guideline [2] provides limitations for structural steel members, based on the maximum ductility and rotation angle of beams, columns and braces. The current study, however, considers the nonlinear force-displacement relations recommended by the Federal Emergency Management Agency (FEMA) [24] instead (Figure 8), because of the more detailed failure criteria presented in FEMA as compared to the GSA guidelines. According to the DoD [3], it is presumed that the entire structural members are at normal temperature throughout the progressive collapse event.

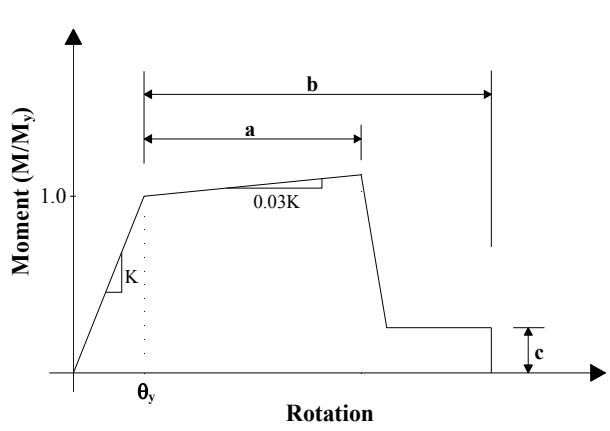

(a)

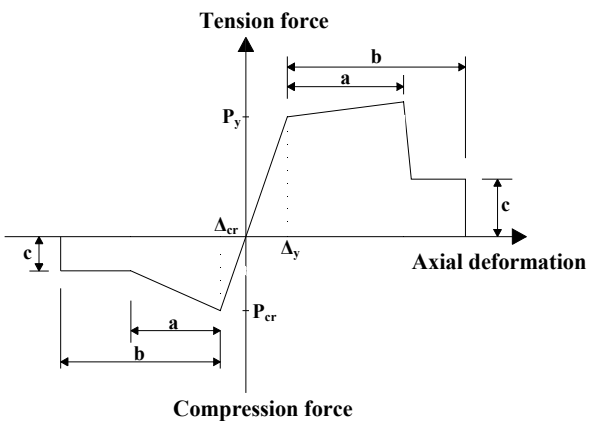

(b)

Figure 8. Force-displacement Relations used for (a) Flexural Members and (b) Braces, according to FEMA 356 [24]

\subsubsection{Validation of the progressive collapse analysis model}

To ensure the accuracy of the proposed FE model described in Section 3.2 for progressive collapse analysis, a one-storey structural plane frame involving four bays is simulated in the SAP2000 [17], as shown in Figure 9.

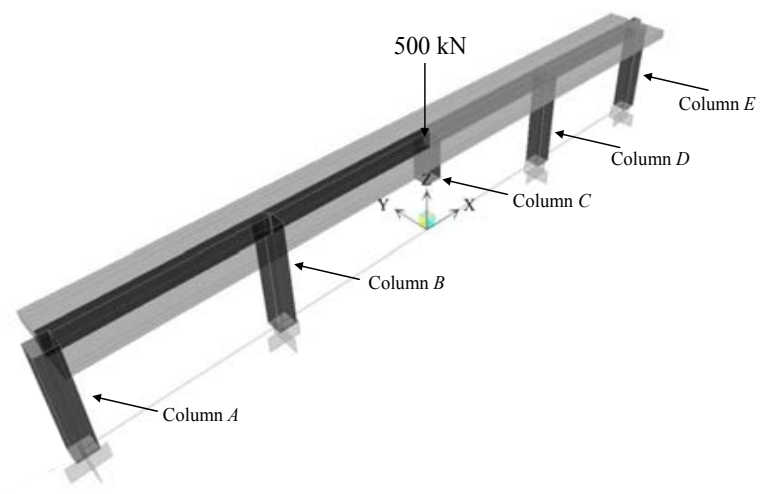

Figure 9. Load and Boundary Condition of the Proposed FE Model for Validation

The validating model duplicates a 1/3-scale testing of a composite plane frame conducted by Guo et al., [25]. The referenced experiment simulated the progressive collapse of a structural frame subjected to a sudden loss of the middle column. The test simulation carried out was based on similar techniques considered for modelling the prototype structure, as mentioned in Section 2 of this paper. In terms of elemental properties, the section sizes and boundary conditions are the same as those considered in the test. A concise description of the section sizes and properties is provided in Table 3. 
Table 3. Section Sizes and Properties used in the Validating Model under Progressive Collapse Analysis

\begin{tabular}{lccccccc}
\hline \multirow{2}{*}{$\begin{array}{c}\text { Element } \\
(\mathrm{mm})\end{array}$} & \multicolumn{2}{c}{ Section* } & \multicolumn{2}{c}{$f_{y}(\mathrm{MPa})$} & \multicolumn{2}{c}{$f_{u}(\mathrm{MPa})$} & \multicolumn{2}{c}{$E_{s}\left(10^{5} \mathrm{MPa}\right)$} \\
\hline Beam & Flange $\quad$ Web & Flange & Web & Flange & Web & Flange & Web \\
Column & $\mathrm{H} 200 \times 100 \times 5.5 \times 8$ & 269 & 275 & 401 & 411 & 1.96 & 2.09 \\
\hline
\end{tabular}

*The dimensional order is: H-overall depth $(d) \times$ flange width $\left(b_{f}\right) \times$ web thickness $\left(t_{w}\right) \times$ flange thickness $\left(t_{f}\right)$

For comparison with the referenced experiment by Guo et al. [25], we have taken into account in the validating model the same specifications and settings adopted by them. Reinforced concrete (RC) slabs of $800 \mathrm{~mm}$ width with a thickness of $100 \mathrm{~mm}$ are used in the models. In relation to the reinforcement ratio, a value of $85 \%$ is adopted for meshing the RC slabs. For reinforcing the longitudinal direction, steel bars $12 \mathrm{~mm}$ in diameter as well as two layers of transversal bars $8 \mathrm{~mm}$ in diameter are used within the slabs. Shear studs $16 \mathrm{~mm}$ in diameter are connected to the steel beams, allowing $100 \mathrm{~mm}$ spacing between each. In the experiment [25], all the columns are fixed at the bottom except the one chosen for the column loss scenario. In the FE model also the bottoms of columns are defined as fixed supports, analogous to those set in the test. In order to simulate the column loss, a $500 \mathrm{kN}$ static concentric load is applied at the top location of Column C (Figure 9), as implemented in the test.

Figure 10 compares the vertical displacement of Column $\mathrm{C}$ results from the numerical solution with those obtained experimentally. To foster more confidence in the proposed model, the vertical displacements of Column $\mathrm{C}$ versus horizontal displacement of other intact columns (Columns A, B, D and E in Figure 9) are compared in Figure 11. Altogether, the trends of graphs are closely aligned with very similar values for both approaches, which shows an acceptable agreement between the numerical and experimental simulations (Figs. 10-11).

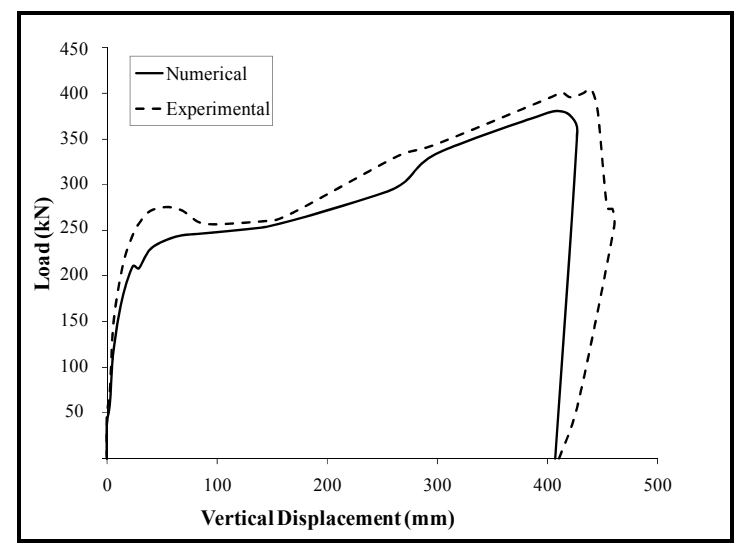

Figure 10. Axial Load versus Vertical Displacement of Column C in the FE model and the Test [25] 


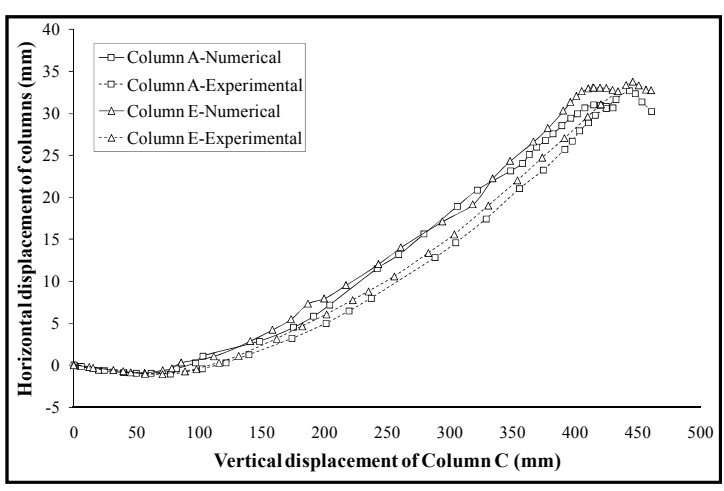

(a) External columns

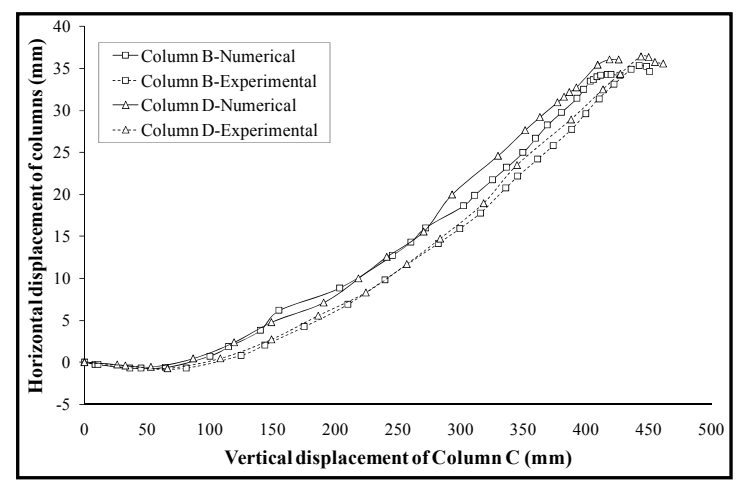

(b) Internal columns

Figure 11. Horizontal Displacement of (a) External and (b) Internal, Intact Columns versus Vertical Displacement of Column C in the FE Model and the Test [25]

The proposed FE model slightly underestimates the displacement of framing columns, as compared with those obtained experimentally. This can be attributed to the identified modelling parameters such as material nonlinearity, which considerably affects the accuracy of numerical results. Besides, since progressive collapse may induce local reverse loading, the accurate depiction of unloading in the constitutive relationships while defining material models can be significant [26]. As we are more concerned with the overall performance of the structure, this model is adequately accurate to perform the progressive collapse analysis.

\subsection{Modelling for Structural Fire Analysis}

After performing the progressive collapse analysis and ensuring the resistance of structural frame against specified column loss scenario, the resistance of the damaged structure against post-event fire was analysed. Figure 12 shows the scheme of damaged structure exposed to fire loading. The heated columns (C2-1 and C4-1 in Figure 5) are subjected to fire on four sides and the heated girders (G2-1 and G3-1 in Figure 5) are exposed on three sides, assuming their top face is sheltered by floor slabs. It is presumed that all heated elements are exposed to temperature rise uniformly across their sections during heating time.

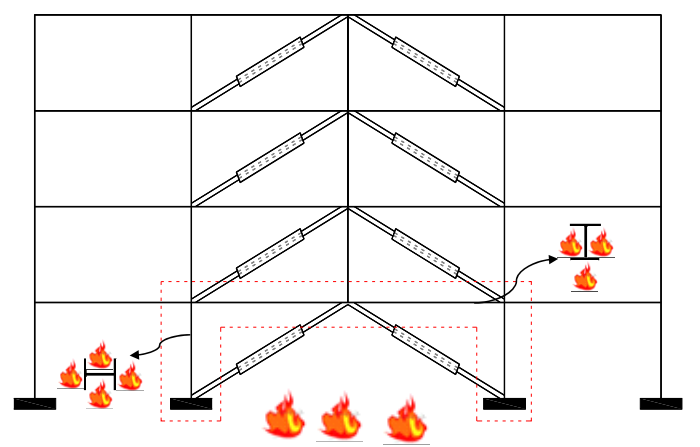

Figure 12. View of Damaged Structural Plane Frame, subjected to the Post-event Fire

As the main aim of this study is to verify the overall influence of BRB systems on the fire resistance of a damaged structure in comparison to OCBs, the bracing elements are assumed to be insulated (remain unheated) throughout the heating time. In this phase of simulation, the model conservatively considers that the whole load redistribution will occur in the parts of the frame above and adjoining the removed column (Figure 12). 
The effects of natural post-flashover are ignored by defining the ISO 834 fire curve [27] in the models. Although this curve does not comprise the cooling phase or account for the compartment properties, it is employed as a relatively conservative approximation to track the ultimate failure by exposing the damaged building to long-term duration of elevated temperatures. The structure is assumed to be a typical office building with a total line load of $40 \mathrm{kN} / \mathrm{m}$ in fire condition. Structural elements in the buildings are modelled as an assemblage of finite beam-columns, braces and connections. In Vulcan, the beam-columns are represented by three-node line elements with two Gaussian integration points along their length. The buckling-restrained braces are modelled implicitly, using three-node line elements. BRB sections are defined as concrete-filled hollow steel elements with the core inside and the clearance between the steel core and the restrainer is modelled using the gap elements in Vulcan. To simulate the restraining system provided by the concrete and the steel casing on the core in preventing the buckling of BRB elements, the in- and out-of-plane rotations of the steel core are restrained. In Vulcan, temperature-dependent mechanical properties for steel recommended by Eurocode 3 (EC 3) Part 1.2 [28] are adopted, as shown in Figure 13 (a). The average value of the coefficient of thermal expansion for steel material $\left(1.4 \times 10^{-5} /{ }^{\circ} \mathrm{C}\right)$, recommended by EC3, is used. Thermal properties of concrete at elevated temperature are extracted from Eurocode 4 (EC 4) Part 1.2 [29], as shown in Figure 13(b). Moisture content of $3 \%$ is adopted for the concrete. The effect of creep in the steel at high temperatures is considered implicitly in the stress-strain relations as proposed in EC3. All possible nonlinearities such as geometric nonlinearities are also considered in the model. To account for the influence of floor slabs on temperature distribution within the beams, it is presumed that the temperature of the heated beam at the top flange is $70 \%$ of the temperature at its bottom flange and web.

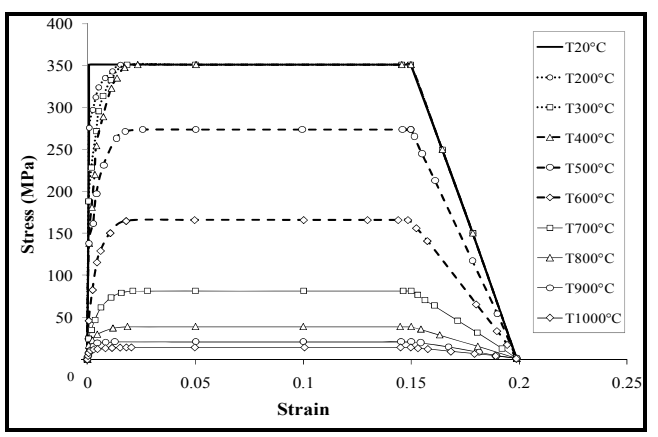

(a)

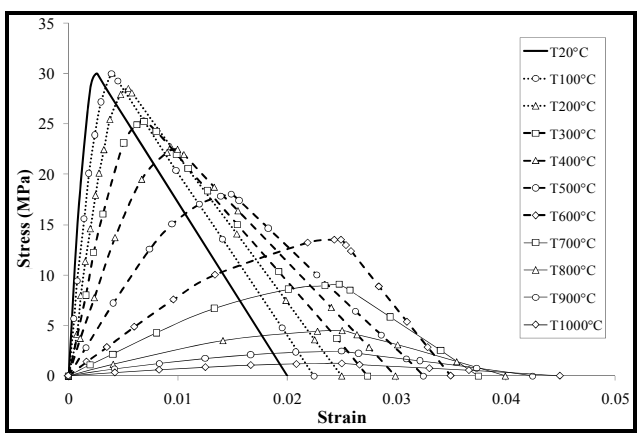

(b)

Figure 13. Stress-strain Relationship of (a) Steel and (b) Concrete, at Elevated Temperature

\subsubsection{Validation of the structural fire analysis model}

The accuracy of the proposed model for structural-fire analysis (described in Section 3.3) is verified by comparing the FE results with those measured in a test carried out by Rubert and Schaumann [30]. As demonstrated in Figure 14, the model comprises of two structural plane frames, an L-shaped span (Figure 14 (a)) and a one-storey double span frame (Figure 14 (b)). For comparison between the numerical results and the test data, the current study makes the same assumptions as those considered in the experiment [31]. The modelled frames were all uniformly heated, using the standard ISO 834 [27] fire curve. The structural elements were made of IPE80 profiles of I-section. 


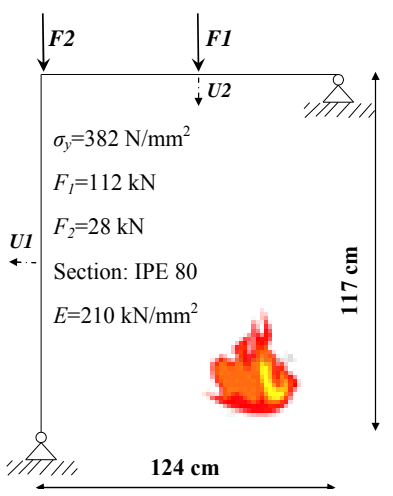

(a)

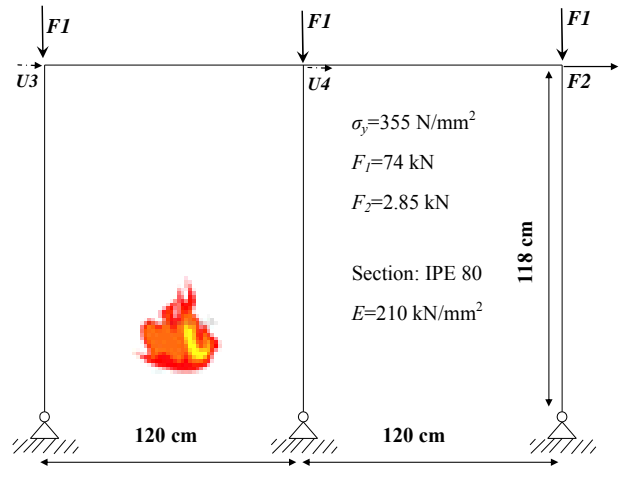

(b)

Figure 14. Structural Steel Frames Tested in Fire by Rubert and Schaumann [30]

Figure 15 compares the displacements at different locations within the modelled frames for the FE solution and the test observations. It can be seen that the results generated by the current model are in good agreement with the experimental data. Hence, this model is adequately accurate to perform the structural-fire analysis using the Vulcan program.
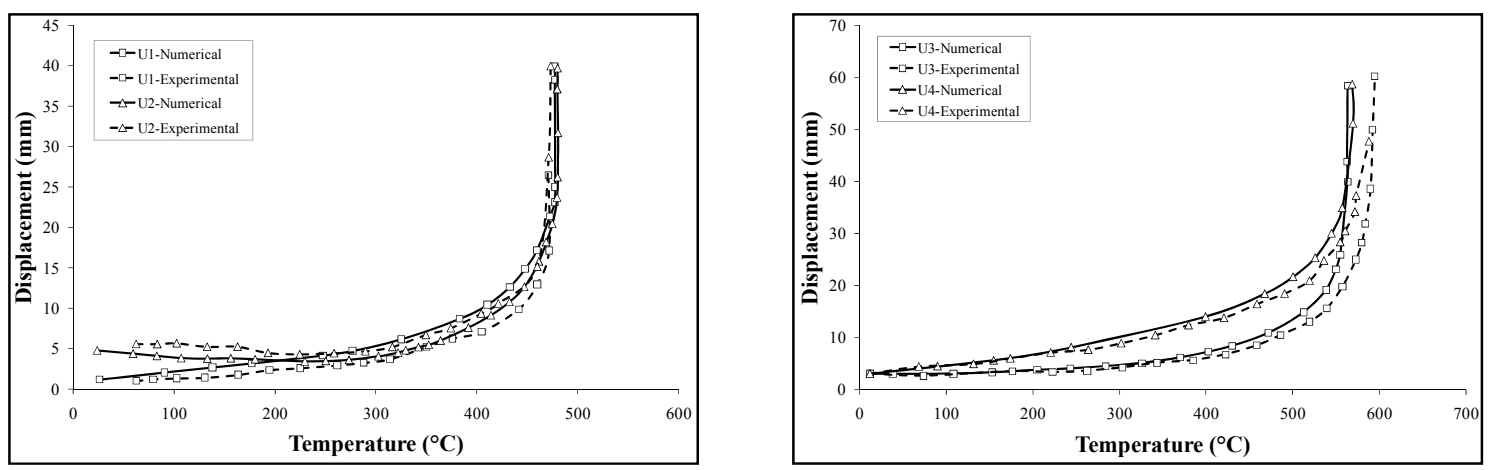

Figure 15. Comparison of Displacement at Different Locations within the Frames between the proposed FE Model and the Test [30] Results

\section{RESULTS AND DISCUSSION}

\subsection{Progressive Collapse Analysis}

The study presented in this paper focuses on the first-storey middle column removal shown in Figure 5 as C3-1. The specified scenario stands for one of the most typical and most critical framing column losses. This could be attributed to a higher restraint provided by the neighbouring elements onto the centre column, resulting to the earlier failure of the corresponding column because of the highest axial force experience within it. In order to track the progressive collapse mechanism and to ensure the resistance of the structural frame against progressive collapse under the specified damage scenario, two analyses are performed in the SAP2000 [17]. The results of each analysis are discussed next.

\subsubsection{Static pushdown analysis}

Nonlinear pushdown (vertical pushover) analysis is performed such that the middle column at the ground level (C3-1 in Figure 5) is removed and the vertical displacement at the top point 
location of the corresponding column (Joint A in Figure 7) is increased gradually afterwards. In the pushdown analysis, the maximum strength with a value of less than 1.0 reveals that the structural frame is not strong enough to withstand the $2(\mathrm{DL}+0.25 \mathrm{LL})$ load amount proposed by GSA guideline [2]. With respect to this criterion, the pushdown curve is represented in Figure 16 for examining the progressive collapse resistance of a structural frame.

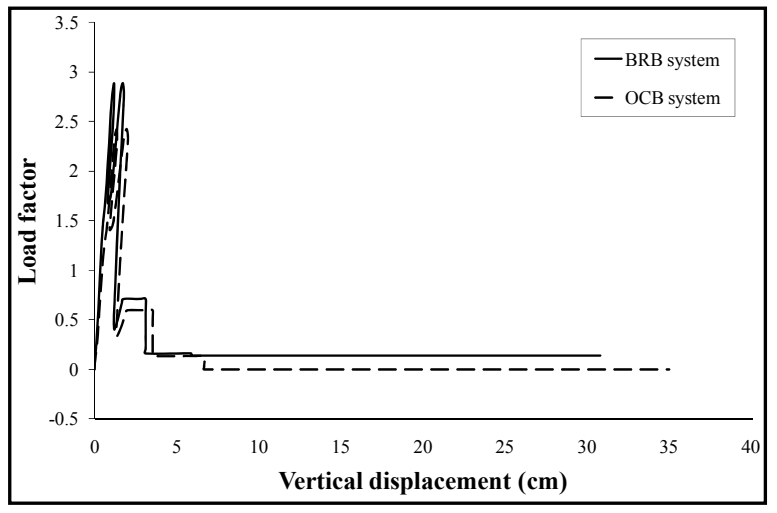

Figure 16. Comparison of Pushdown Curves Versus Vertical Displacement for Both Bracing Systems

Figure 16 shows that the load factor attains a maximum value of 2.78 and 2.45 in BRBs and OCBs, respectively. This is followed by an abrupt reduction in the strength, caused by further increase of vertical displacement after the maximum strength is gained, for both bracing systems.

The variation of axial forces within failed elements for both bracing systems is illustrated in Figure 17, in which the elemental failure sequence is represented by the number order, i.e., 1, 2,3 , etc. In this figure, the member forces are normalized by dividing the compressive member forces by the buckling load, $P_{c r}$, and tensile member forces by the yielding load, $P_{y}$.

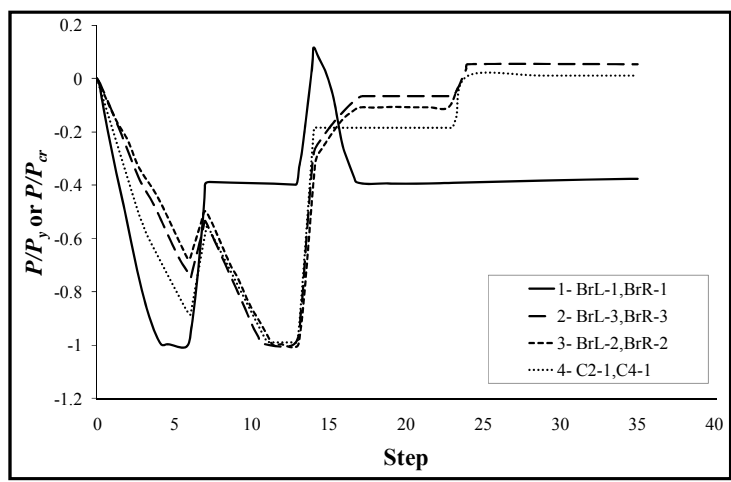

(a)

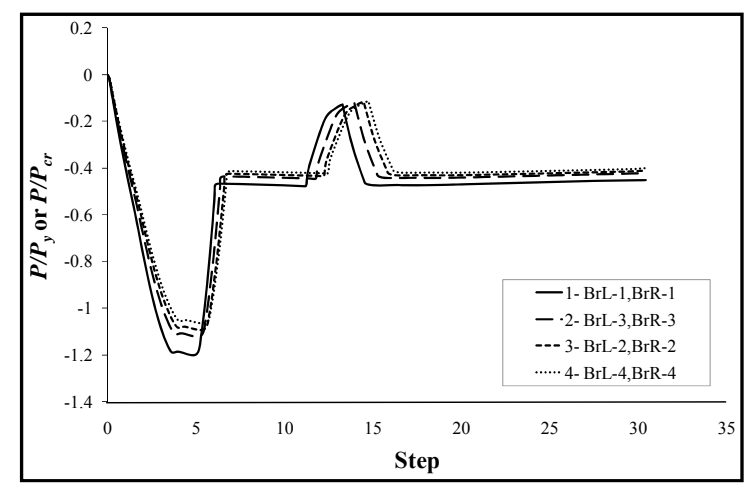

(b)

Figure 17. Variation of Axial Force within Failed Elements in (a) OCB and (b) BRB System

Figures 16-17 reveal that both $\mathrm{BRB}$ and $\mathrm{OCB}$ systems meet the acceptance criterion according to GSA [2], i.e., maximum strength $>1$. Hence, the selected structural frame is capable of resisting the progressive collapse due to the designated column loss scenario. It is worth mentioning that although both bracing systems adequately resist progressive collapse, the resistance provided by BRBs is higher than that of OCBs, owing to the higher stiffness the former provides to the structural frame. 


\subsubsection{Nonlinear dynamic time history analysis}

As mentioned in Section 2.1, the nonlinear dynamic analysis is performed by abruptly eliminating the reactions acting on the lost column (Figure 3 (c-d)). Figure 18 shows the vertical displacement at the top point location of the removed column (Joint A in Figure 7), resulted from the nonlinear dynamic time history analysis. In Figure 18, the horizontal marked lines represent the vertical displacement of the corresponding column resulting from the linear static analyses for the condition whereby the structural frame is subjected to the DL+0.25LL load combination.

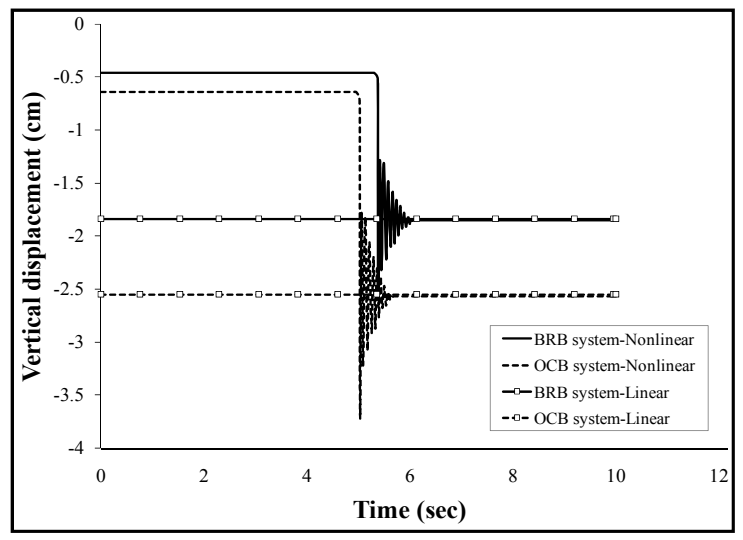

Figure 18. Vertical Displacement at the Top Point Location of Removed Column for Both Bracing Systems

Figure 18 shows that the dynamic response slowly converges to that of the static analysis (without imposing the dynamic amplification factor of two). Evidently, the constant values resulting from the linear elastic responses are almost identical to the corresponding steady dynamic values, for both resistance systems. This means there is no permanent deformation and the structural frame's behaviour remains elastic for both BRB and OCB systems. Accordingly, the structural frame is capable of resisting progressive collapse due to the specified column loss scenario in both BRBs and OCBs. The only difference is that the progressive collapse resistance provided by BRBs is higher than that of ordinary systems. The higher maximum load factors, which resulted from the static push down analyses, with the smaller vertical displacements at Joint A of the Column C3-1 resulting from nonlinear dynamic response for BRBs, offer good evidence of the system better resisting capability. By ensuring the progressive collapse resistance, the damaged building is now ready to be analysed under the post-event fire. The results of structural-fire analysis are discussed next.

\subsection{Structural-Fire Analysis}

The temperature distribution within the heated beams and columns (shown in Figure 12) against elapsed heating time is represented in Figure 19 based on the modelling approach discussed earlier in Section 3.3. Results show that the average temperatures experienced by the heated columns are higher than those of the heated beams. This can be attributed to the influence of floor slabs, which shield the top face of heated beams from fire. 


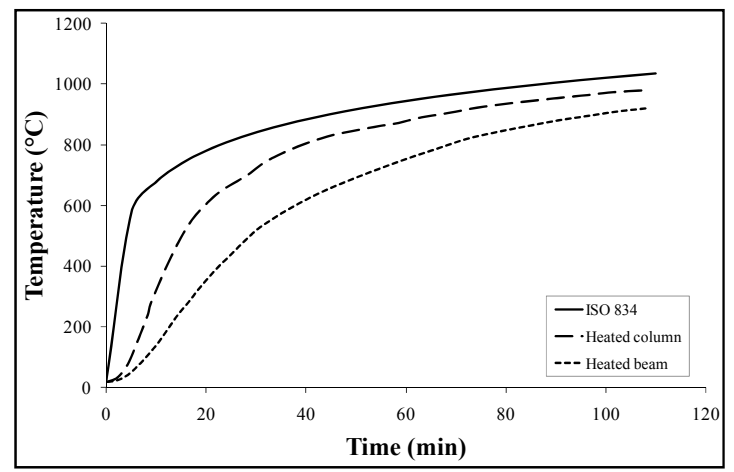

Figure 19. Temperature-time History within the Cross-section of Heated Elements subjected to the ISO 834 Fire Curve

By increasing the heating time in the damaged structure, the top point of the removed column (Point $R$ " for OCBs in Figure 20(a)) tends to move downwards and as a direct result, the axial force within the braces and the intact columns (adjacent to the lost column) rises. This process is continued until the column reaches its yield strength, leading to the failure of adjacent members. The final state of failure for the structural frame with both bracing systems is illustrated in Figure 20.

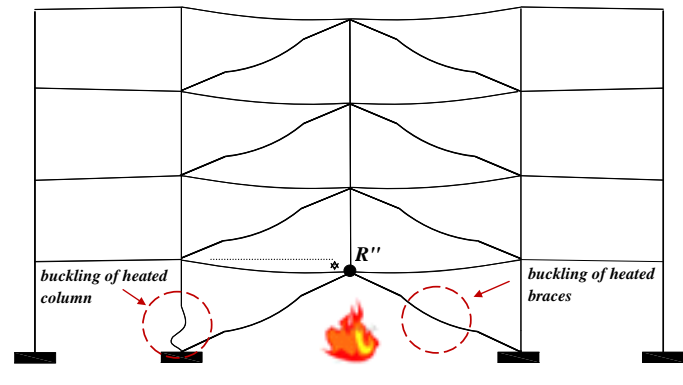

(a)

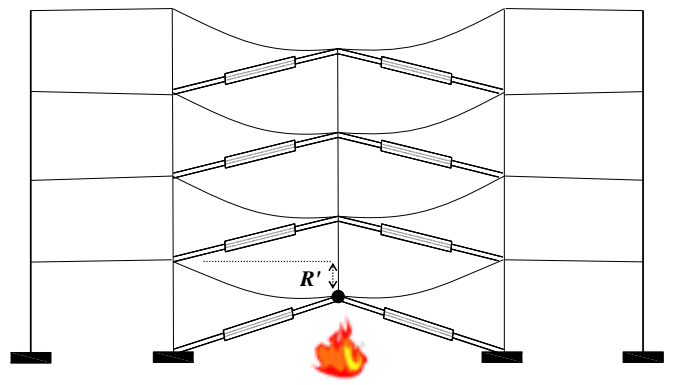

(b)

Figure 20. Failure Scheme of a Damaged Structure with (a) OCB and (b) BRB Systems, after Exposure to Post-event Fire

In the damaged structure restrained with the OCB system, the deflection experienced by the heated girders at the location of the removed column $\left(R^{\prime \prime}\right.$ in Figure 20 (a)) is less than that of the BRB system $\left(R^{\prime}\right.$ in Fig 20 (b)). This phenomenon corresponds to the failure process of the structural frame with BRB and OCB systems. In terms of the failure scheme of a damaged building exposed to fire, the response of a structure with OCBs is such that the braces on the ground level yield first. This is followed by the buckling of braces on the second and third storeys before they reach their full capacity and leads to the buckling of the heated column on the first storey (Figure 20 (a)). With the buckling of the column, the building with an OCB system loses the majority of its strength and the structural global failure starts. In contrast, the structural frame with a BRB system remains stable, thanks to the buckling-resistant characteristic of braces, which leads to braces solely maintaining the overall stability of the building during fire (Figure 20 (b)). Consequently, it can be seen that at the moment when the damaged structure with OCB has lost most of its strength, the same building with a BRB system is able to resist further girder deflection and higher axial forces induced within the columns and braces due to fire loading. 
Figure 21 compares the deflection of heated girders (G2-1 and G3-1 in Figure 5) at the vicinity of removed column for the structural frame restrained with BRB and OCB systems. Results show that through the weakening of heated girders, the damaged structure experiences a slow increase in deflection until it reaches a value of $323 \mathrm{~mm}$ after 76 minutes (Point $A^{\prime}$ in Figure 21) and $397 \mathrm{~mm}$ after 72 minutes (Point $A^{\prime \prime}$ in Figure 21) in BRBs and OCBs, respectively. At this point, the deflection curve quickly rises to a value of $393 \mathrm{~mm}$ (Point $B^{\prime}$ in Figure 21) in BRBs while there appears no increase for OCBs. This is because the buckling restrained braces append an additional strength to the damaged structure owing to the buckling-resistant behaviour of the braces, as compared to OCBs. As a direct result, for the BRB structural frame the failure starts in the girders after the braces reach their yield strength and fail with no signs of buckling in the framing columns (Figure 20 (b)). In contrast, for OCBs the braces fail before reaching their full capacity, leading to the participation of the first-storey column to resist the post-event fire. Hence, the girder deflection for the damaged building with the ordinary system is similar to that of BRBs, until the fire loaded column fails (Figure 20 (a)) and as a result, there is no further increase in the deflection curve of heated girders for OCBs (Point $A$ " in Figure 21).

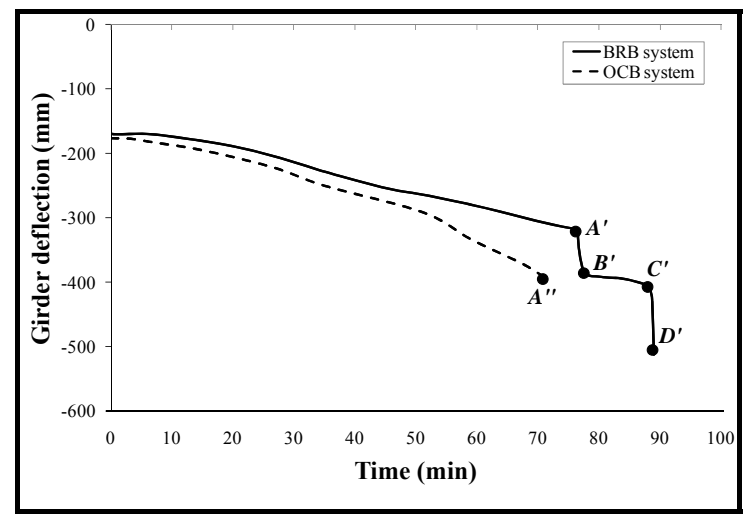

Figure 21. Girder Deflection at the Top Point of Removed Column caused by Temperature Rise

Apparently, the structural frame with BRBs experiences a sharp slope in the heated girder's deflection from Point $A^{\prime}$ to Point $B^{\prime}$ (Figure 21). This quick rise may be attributed to the occurrence of plasticization in the fire loaded girders. The plasticized steel elements begin to unload when they reach the $15 \%$ strain and continue unloading until attaining the ultimate strength at $20 \%$ strain [30]. At this point, i.e., 20\% strain, the structural steel member is unable to carry any further load. For a comprehensive scheme on this phenomenon, the variation of strain against elapsed heating time is shown for the girders within the damaged structure in Figure 22, for both bracing systems. 


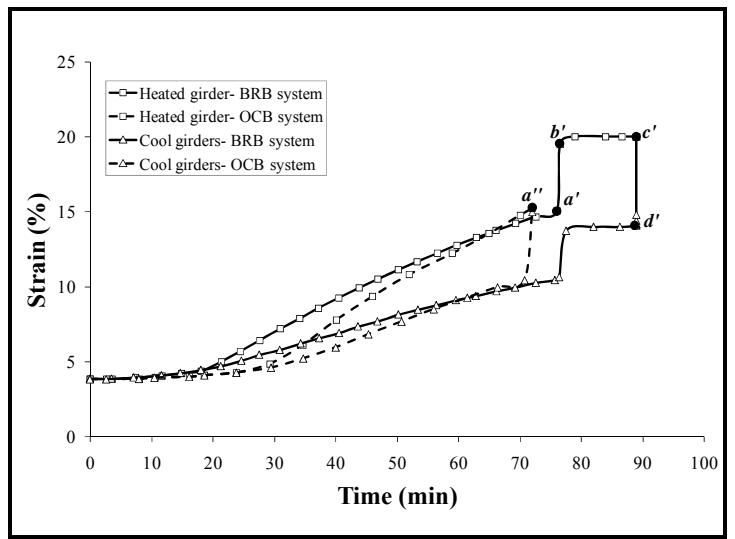

Figure 22. Development of Strain within the Girders of Damaged Structures due to Fire Loading

Obviously, a maximum strain within the heated girders reaches $15 \%$ prior to the occurrence of a further rapid rise in the girder's deflection (shown as Points $A^{\prime}$ and $A^{\prime \prime}$ in Figure 21 for BRBs and OCBs, respectively). In terms of $15 \%$ strain, it can be seen that the heated girders in the damaged building with BRBs gain the corresponding value after 76 minutes of burning (Point $a^{\prime}$ in Figure 22). Similarly, in the structural frame with OCBs, the fire loaded girders reach $15 \%$ strain after 72 minutes (Point $a^{\prime \prime}$ in Figure 22). After the 15\% strain is reached, there appears an abrupt increase in the strain until the girder gains an ultimate value of $20 \%$ after 86 minutes (Point $b^{\prime}$ in Figure 22) in BRBs. At this point, there is no additional increase in the strain curve of girders for OCBs due to first-storey column failure prior to girders reaching further strain. In BRBs, once the heated girder reaches $20 \%$ strain it fails and sheds its load to the cooler girders. The maximum strain experienced by the cooler girders in BRBs is a good example of unloading action in the heated girders, as shown in Figure 22. According to Eurocode 3 [29], at this point there exists an $18 \%$ decrease in the stiffness with no reduction in the strength. Once the heated girder transfers its carrying load, the framing girders experience an increase in deflection until the cool girders become overloaded and are unable to sustain any further load. A second sudden increase in the deflection curve (shown as line $C^{\prime} D^{\prime}$ in Figure 21) shows this phenomenon, which leads to the global failure of the specified frame with BRBs. At this stage, it can be seen that the BRB system maintains the overall stability of the frame for 89 minutes with a maximum deflection of $511 \mathrm{~mm}$ experienced in the heated girders (Point $D^{\prime}$ in Figure 21).

With respect to the failure process described hitherto for BRBs, in order to follow the final failure scheme of the OCB system and compare it with BRBs, the response of fire loaded columns in a damaged building should be presented. To this end, the development of vertical displacements within the intact columns adjacent to the removed one (C2-1 and $C 4-1$ in Figure 5) is demonstrated in Figure 23. Figure 23 shows that both BRBs and OCBs experience a decrease in the axial displacement of the heated columns after an initial increase. This is attributed to the vertical deflection of heated girders, which impose tensile force within the heated columns (that are connected to the girders) and cause an upward movement of the corresponding columns. Apparently, this decrease continues in BRBs with no sudden increase, meaning that there is no sign of column buckling at the time of structural global failure, i.e., 89 minutes. Inversely, for OCBs the vertical displacement increases dramatically up to a value of $67 \mathrm{~mm}$ after 72 minutes, which shows that the structural failure starts with the buckling of heated columns at 72 minutes. 


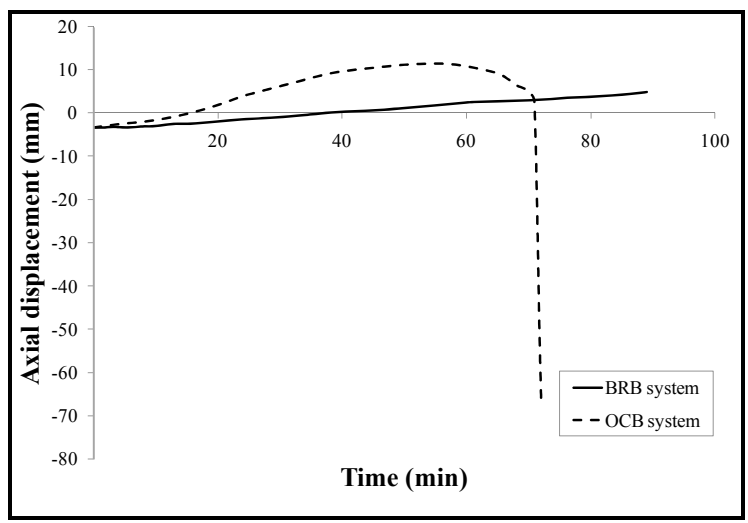

Figure 23. Vertical Displacement Developed within the Fire Loaded Columns (C2-1 and C4-1) adjacent to the Removed Column

To sum up, the final failure of a damaged structure with OCBs is initiated by the failure of the first-storey heated column (Figure 20 (a)) and that of BRBs by the failure of cool framing girders after the failure of braces and heated girders, respectively. BRB elements are able to absorb the thermally induced axial forces and transfer the loads successfully to the adjacent girders, thus, postpone the columns' buckling. Contrary, the ordinary braces buckle before reaching their full capacity, resulting in buckling of the columns after 72 minutes. BRBs sustain the post-event fire for 89 minutes. This indicates that at the time that a damaged structure with OCB system fails because of the post-event fire, a similar building with BRBs can resist the corresponding event for about 17 minutes more.

\section{CONCLUSIONS}

In this paper, the effect of the BRB system in maintaining the overall stability of a damaged building against post-event fire in comparison with the OCB system was investigated, using a multi-hazard approach. For this purpose, a two-dimensional plane frame subjected to the sudden removal of a first-storey centre column was subsequently exposed to the standard fire curve. Considering the superior performance of inverted-V arrangement for bracing elements in resisting progressive collapse, this bracing configuration was modelled and compared for both bracing systems. Several important conclusions can be drawn as follows:

(1) In the BRB system, bracing members behave similarly in both tension and compression. Hence, during a column loss scenario they can withstand higher axial forces without the occurrence of buckling in the bracing member. Whereas, in the OCB system, bracing elements are not as effective as expected, owing to the buckling of the braces.

(2) When a localized failure occurs in the first-storey centre column, buckling restrained bracing members are more efficient in transferring the load previously carried by this column to the other stiffer adjacent elements. This makes the BRB system more efficient in maintaining the structural overall stability due to the sudden column loss, as compared with the ordinary bracing elements.

(3) Although both systems withstand the progressive collapse caused by sudden column loss, it is demonstrated that BRB elements are more effective in redistributing the post-event fire loading from heated elements to the other bays, thanks to their buckling-resistant characteristic. Furthermore, it is observed that a structural frame with BRBs can resist greater axial displacements caused by fire loading, in comparison to OCBs. 
(4) BRB elements are able to absorb the thermally induced axial forces and transfer the loads successfully to the adjacent girders and prevent the columns' buckling. In contrast, the ordinary braces buckle before reaching full capacity, followed by the buckling of first-storey fire loaded columns.

(5) For a damaged structure restrained with the OCB system, the deflection experienced by the fire loaded girders at the location of the removed column is less than that of BRBs. This is attributed to the participation of girders in resisting the fire loading after BRB elements reach their yield strength. In an ordinary system, the first-storey columns contribute structural resistance after the braces yield, follows by a higher displacement developed within the columns.

(6) Because of the greater stiffness of BRBs, they can resist higher axial forces when exposed to the post-event fire loading. Hence, they increase the global collapse time of the damaged structure and there is a significant difference in the structural failure scheme, as compared to that of OCBs.

(7) The final failure of a damaged structure with OCBs is initiated by the failure of the first-storey fire loaded column, while that of BRBs is initiated by the failure of cool framing girders after the failure of braces and heated girders, respectively.

(8) BRBs sustain the post-event fire for 89 minutes, demonstrating that when a damaged structure with OCB system has failed because of the post-event fire after 72 minutes of heating time, a similar building with BRBs can resist the corresponding event for about an additional 17 minutes.

\section{ACKNOWLEDGEMENTS}

The research is financially supported by the Research Management Center (RMC) of Universiti Teknologi Malaysia (UTM) under the post-doctoral fellowship scheme. This support is highly appreciated.

\section{REFERENCES}

[1] Pearson, C. and Delatte, N., "Ronan Point Apartment Tower Collapse and Its Effect on Building Codes", J. Perform Constr. Facil. 2005, Vol. 19, No. 2, pp. 172-7.

[2] U.S. General Services Administration (GSA) Guidelines, Progressive Collapse Analysis and Design Guidelines for New Federal Office Buildings and Major Modernizations Projects; 2003.

[3] Dept. of Defense (DoD), Design of Buildings to Resist Progressive Collapse, Unified Facilities Criteria (UFC) 4-023-03, U.S. Dept. of Defense (DoD): Washington, DC; 2010.

[4] ASCE. Minimum Design Loads for Buildings and Other Structures. Standard ASCE/SEI 7-05. Reston, Virginia, USA: American Society of Civil Engineers; 2005.

[5] Khandelwal, K., El-Tawil, S., Sashi, K. and Lew, H.S., "Macromodel-based Simulation of Progressive Collapse: Steel Frame Structures", J. Struct. Eng. 2008, Vol. 134, No. 7, pp. 1070-8.

[6] Kim, J. and Kim, T., "Assessment of Progressive Collapse-resisting Capacity of Steel Moment Frames”, J. Constr. Steel Res., 2009, Vol. 65, No. 1, pp. 169-79. 
[7] Park, J. and Kim, J., "Fragility Analysis of Steel Moment Frames with Various Seismic Connections subjected to Sudden Loss of a Column”, Eng. Struct. 2010, Vol. 32, No. 6, pp. 1547-55.

[8] Kim, J., Lee, Y. and Choi, H., "Progressive Collapse Resisting Capacity of Braced Frames", Struct. Des. Tall Spec. Build, 2011, Vol. 20, No. 2, pp. 257-70.

[9] Fu, F., "3-D Nonlinear Dynamic Progressive Collapse Analysis of Multi-storey Steel Composite Frame Buildings-parametric Study”, Eng. Struct., 2010, Vol. 32, No. 12, pp. 3974-80.

[10] Mohamed, O.A., "Assessment of Progressive Collapse Potential in Corner Floor Panels of Reinforced Concrete Buildings", Eng. Struct., 2009, Vol. 31, No. 3, pp. 74957.

[11] Khandelwal, K., El-Tawil, S. and Sadek, F., "Progressive Collapse Analysis of Seismically Designed Steel Braced Frames”, J. Constr. Steel Res., 2009, Vol. 65, No. 3, pp. 699-708.

[12] Xie, Q., "State of the Art of Buckling-restrained Braces in Asia", J. Constr. Steel. Res. 2005, Vol. 61, No. 6, pp. 727-48.

[13] Sahoo, D.R. and Chao, S.H., "Performance-based Plastic Design Method for Buckling Restrained Braced Frames", J. Eng. Struct., 2010, Vol. 32, pp. 2950-58.

[14] Talebi, E., Tahir, M., Zahmatkesh, F. and Kueh, A., "Fire Response of a 3D MultiStorey Building with Buckling Restrained Braces. Lat Am J. Solids Stru., 2015, Vol. 12, No. 11, pp. 2118-42.

[15] Della-Corte, G., Landolfo, R. and Mazzolani, F.M., "Postearthquake Fire Resistance of Moment Resisting Steel Frames", Fire Saf. J., 2003, Vol. 38, pp. 593-612.

[16] Chen, H. and Liew, J.Y.R., "Explosion and Fire Analysis of Steel Frames using Mixed Element Approach", J. Eng. Mech., 2005, Vol. 131, No. 6, pp. 606-16.

[17] SAP2000. Version 14.0, Analysis Reference Manual, Computers and Structures (CSI), Inc.: Berkeley, CA; 2009.

[18] Vulcan. Vulcan Analysis User's Manual, Version 10.12.0, U.K; 2000.

[19] Huang, Z., Burgess, I.W. and Plank, R., "Three-Dimensional Analysis of Reinforced Concrete Beam-Column Structures in Fire”, Eng. Struct., 2009, Vol. 135, pp. 1201-12.

[20] Kokot, S., Anthoine, A., Negro, P. and Solomos, G., "Static and Dynamic Analysis of a Reinforced Concrete Flat Slab Frame Building for Progressive Collapse", Eng. Struct. 2012, Vol. 40, pp. 205-17.

[21] AISC. Load and Resistance Factor Design Specification for Structural Steel Buildings, American Institute of Steel Construction : Chicago, 2005.

[22] AISC. Seismic Provisions for Structural Steel Buildings. American Institute of Steel Construction: Chicago, 2010.

[23] IBC. International Building Code. International Code Council: Falls Church, VA, 2006.

[24] Federal Emergency Management Agency (FEMA). Prestandard and Commentary for the Seismic Rehabilitation of Buildings, FEMA-356: Washington, D.C., 2000.

[25] Guo, L., Gao, S., Fu, F. and Wang, Y., "Experimental Study and Numerical Analysis of Progressive Collapse Resistance of Composite Frames", J. Constr. Steel Res. 2013, Vol. 89, pp. 236-51.

[26] Kwasniewski, L., "Nonlinear Dynamic Simulations of Progressive Collapse for a Multistory Building”, Eng. Struct. 2010, Vol. 32, pp. 1223-35.

[27] ISO (International Standards Organization). ISO 834: Fire Resistance Tests, Elements of Building Construction, Switzerland: International Standards Organization, 1980.

[28] EC3. Eurocode 3: Design of Steel Structures-part 1-2: General Rules -Structural Fire Design, British Standards Institution, BS EN 1993-1-2: London, UK, 2005. 
[29] EC4. Eurocode 4: Design of Composite Steel and Concrete Structures- Part 1-2: General Rules-structural Fire Design, British Standards Institution, BS EN 1994-1-2: London, UK, 2005.

[30] Rubert, A. and Schaumann, P., "Structural Steel and Plane Frame Assemblies under Fire Action, Fire Saf. J., 1986, Vol. 10, pp. 173-84. 